\title{
Buluggīn B. Zīrī
}

\section{Golvin}

\section{OpenEdition}

Journals

Édition électronique

URL : http://journals.openedition.org/encyclopedieberbere/1881

DOI : 10.4000/encyclopedieberbere.1881

ISSN : 2262-7197

\section{Éditeur}

Peeters Publishers

\section{Édition imprimée}

Date de publication : 1 septembre 1992

Pagination : 1653-1657

ISBN : 2-85744-581-4

ISSN : 1015-7344

\section{Référence électronique}

L. Golvin, «Buluggīn B. Zirī », Encyclopédie berbère [En ligne], 11 | 1992, document B114, mis en ligne le 01 avril 2013, consulté le 25 septembre 2020. URL : http://journals.openedition.org/ encyclopedieberbere/1881; DOI : https://doi.org/10.4000/encyclopedieberbere.1881

Ce document a été généré automatiquement le 25 septembre 2020

(c) Tous droits réservés 


\section{Buluggīn B. Zīrī}

\section{Golvin}

1 La fortune des Zīrides est liée étroitement à celle des premiers califes fātțtimides en Ifrīqiya. On sait que rôle devait jouer Zīīi, le fils de Manād pour assurer le succès de cette entreprise orientale et pour sauver la dynastie encore bien fragile lors de l'équipée d'Abū Yazīd, le fameux « homme à l'âne ». Il semble que très tôt, Buluggīn ait été associé à la gloire de son père si l'on tient pour vraisemblable le récit d'Ibn Hुaldūn (Berbères II, 6), qui dit que le chef berbère autorisa son fils Buluggūn à fonder trois villes : Alger, Miliana et Médéa (349/960). Déjà, l'autorité des Zīrides s'était affirmée par la fondation d'une véritable capitale en pleine montagne de Titteri: Achīr (324/935-6).

2 Cependant, l'heure de Buluggīn devait sonner après la mort de son père tué au combat contre les Zanāta, près de Tiaret (360/971).

3 On épiloguera sans doute encore longtemps sur les raisons qui amenèrent le calife fāṭimide al-Mu'izz li-dīn-llāh à confier la lieutenance du royaume mağribin à Buluggīn au moment où, réalisant enfin les vœux de ses aïeux, il se mettait en route pour l'Égypte (fin 361/oct. 971). Tout semblait militer en la faveur de Ǧa'far b.'Alī b. Ḥamdūn, héritier d'une grande famille andalouse, ralliée depuis longtemps à la cause fāațimide et qui régnait sur un fief dont M'sila était la capitale. Le contraste entre ce seigneur arabe, aux mœurs raffinées et le fils de Zīrī, montagnard berbère, un rural à peine arabisé, était, sans aucun doute saisissant. Par ailleurs, outre ce prétendant qui semblait le favori, on comptait d'autres chefs berbères, notamment chez les Kutāma, alliés de la première heure et tout dévoués à la cause des šĩites. En fait, Buluggīn sut manœuvrer, semble-t-il, avec une grande habileté en compromettant l'orgueilleux et imprudent Ğa'far, au demeurant trop ambitieux pour rassurer pleinement al-Mu'izz. Ce rival écarté, Buluggīn s'imposait. Il sut en l'occurrence, manifester une humilité de bon aloi et apporter aux Fāțimides des preuves convaincantes de sa loyauté à la suite d'une entrevue relatée par Maqrīzī (Itti‘āz, p. 142-143). Le calife, rassuré, aurait alors donné pour consigne à son futur lieutenant : 1 . de ne jamais exempter les ruraux de l'impôt ; 2 . de tenir toujours brandi le sabre sur la tête des Berbères (il faut entendre les Zanāta); 3. de ne jamais nommer à un poste d'autorité un de ses proches parents; 4 . d'accorder 
ses faveurs aux citadins. De plus, étaient exclus de l'héritage la Sicile dont le gouverneur dépendait directement du Caire ainsi que Tripoli (c'est-à-dire l'actuelle Libye).

4 Revêtu des insignes du pouvoir - robe d'honneur, chevaux richement harnachés, officiellement reconnu sous le nom d"Abd Allāh abū'l-Futūh Yūzuf b.Zīrī, le berbère devait rester avant tout et jusqu'à sa mort «le chef des Șanhāğa et le souverain d'Achîr » (Idris, p. 39). Il se fait édifier, à proximité de cette capitale, un palais de pure tradition orientale (vraisemblablement inspiré de Sabra al-Manșūriyya ou, plus sûrement, de ceux de Mahdiya (L. Golvin, Le palais de Zîrī) et il vient régulièrement séjourner dans cette résidence où il se trouve parfaitement à l'aise lorsque les affaires de l'état lui donnent l'occasion de s'absenter de Kairouan. La lutte incessante contre l'ennemi traditionnel, les Zanāta, soutenus de plus en plus ouvertement par les Umayyades de Cordoue, font de la forteresse du Titteri un point d'appui et une base de départ de toute première valeur. En ramad̄ān 362/juin 973, Buluggīn lance une grande offensive de pacification sur Achîr, les nouveaux arrivants y fondent un quartier que, fort curieusement, ils nomment Tlemcen (al-Nuwayrī). En l'occurrence, l'Emir ne devait pas s'aventurer au-delà vers l'ouest par ordre de son suzerain. Outre cette grande expédition, Buluggīn eut à réprimer quelques mouvements séditieux au Magrib central, tel celui de Halaf b.Hुayr à Baghai (365/975), mais il sut, à chaque fois, se tirer victorieusement de ces entreprises et tenir solidement en main l'empire qui lui avait été confié. Plus dangereuse cependant devait être la dernière aventure de l'Émir au Mag̉rib central car il ne trouvait pas seulement devant lui les Zanāata qu'il connaissait bien, mais une véritable coalition orchestrée par le dictateur andalou Ibn Abī 'Āmir qui gouvernait alors l'Espagne musulmane au nom du calife réduit au rôle de fantoche. Grâce à cet appui, le chef zénète Hुazrun b.Fulful avait réussi à s'emparer pour un temps de Sigilmāsâ (367/978) et il prenait alors la tête des forces opposées aux Fāțimides et à leurs alliés zīrides.

5 Bulugginn ne fut pas long à répliquer, le temps de constituer une puissante armée, il traversa tout le Maǵrib central en 368/979 sans rencontrer d'opposition, il entra à Fès en vainqueur en $369 / 980$; de là, il fonça sur Siğilmāsa d'où il délogeait les Zanāta, massacrant leur chef; il les poursuivit jusqu'à Tanger qu'il n'osa cependant pas attaquer, vivement impressionné qu'il fut par l'importance des renforts envoyés d'Espagne. Il renonça également à attaquer Ceuta et il se rabattit alors sur les Barg̉awāta, tribu berbère où triomphait une hérésie bien connue, et, massacrant son faux prophète Șâliḥ ainsi que ses adeptes, il réduisit en esclavage femmes et enfants. Après quoi, il reprit le chemin de l'Ifrīqiya mais il dut faire volte-face avant d'atteindre son but, les Mağrāwa (zénètes) ayant réoccupé les territoires perdus, y compris Siğilmāsa. Le zīride ne devait cependant pas mener à bien cette nouvelle expédition, la maladie le terrassant et le contraignant à s'arrêter en route. Il mourut aux environs de Taza le 21 dü'l-Hiğğg 373/25 mai 984.

6 On peut être surpris de la fidélité sans faille de Buluggīn à des maîtres si éloignés et, au demeurant, assez peu regrettés des kairouanais. Ces derniers avaient, en effet, toujours résisté à la doctrine šìite et ils l'avaient combattue souvent ouvertement. On ignore quelle pouvait être la profondeur des convictions du chef berbère en matière religieuse, mais on peut supposer qu'il ne fit rien pour éveiller les susceptibilités des doctes ūlamā' d'Ifrīqiya attachés à l'orthodoxie sunnite. En fait, le pouvoir du «lieutenant » était essentiellement militaire. Il avait dû accepter (Maqrīzī prétend qu'il l'avait lui-même 
sollicité), de partager son autorité civile avec quelques hauts fonctionnaires nommés directement par le calife. Cette situation ambiguë ne devait pas manquer, tôt ou tard, de soulever de sérieux problèmes.

7 A dire vrai, les rivalités se manifestèrent surtout entre ces hauts fonctionnaires, notamment entre Ziyādat Allāh b.'Abd Allāh b.al-Qadīm, nommé par al-Mu'izz au poste de percepteur des impôts et 'Abd Allāh b.Muhammad al-Kātib, nommé par Buluggīn au gouvernorat de Kairouan et de Șabra al-Manșūriyya. Bien qu'ayant dû accepter contre son gré ce poste important, 'Abd Allāh eut à cœur de conduire les affaires de l'état de son mieux et en toute indépendance. Il se heurta ainsi à Ziyādat Allāh et leur rivalité (d'autant plus étonnante qu'ils étaient tous deux d'authentiques descendants des Ağlabides) devait susciter de graves troubles à Kairouan. Buluggīn, en expédition au Magrib, soutint vraisemblablement «son » gouverneur qui finit par faire emprisonner son rival. Ce dernier mourut en 366/977 sans avoir été libéré (Bayān). On ne peut prétendre, faute de preuves, que cet incident marquait de la part du zīride un désir d'indépendance à l'égard du Caire, mais il faut se rappeler qu'en d'autres occasions, Buluggin sut opposer une fin de non recevoir aux ordres émanant du calife, notamment lorsque, en pleine offensive contre les Zanāta, le chef berbère reçut, en 371/982, une invitation pressante d'avoir à envoyer au Caire mille cavaliers et les plus valeureux de ses frères. Les arguments présentés par l'Émir suffirent à convaincre le calife.

Le plan de l'Achir de Buluggin.

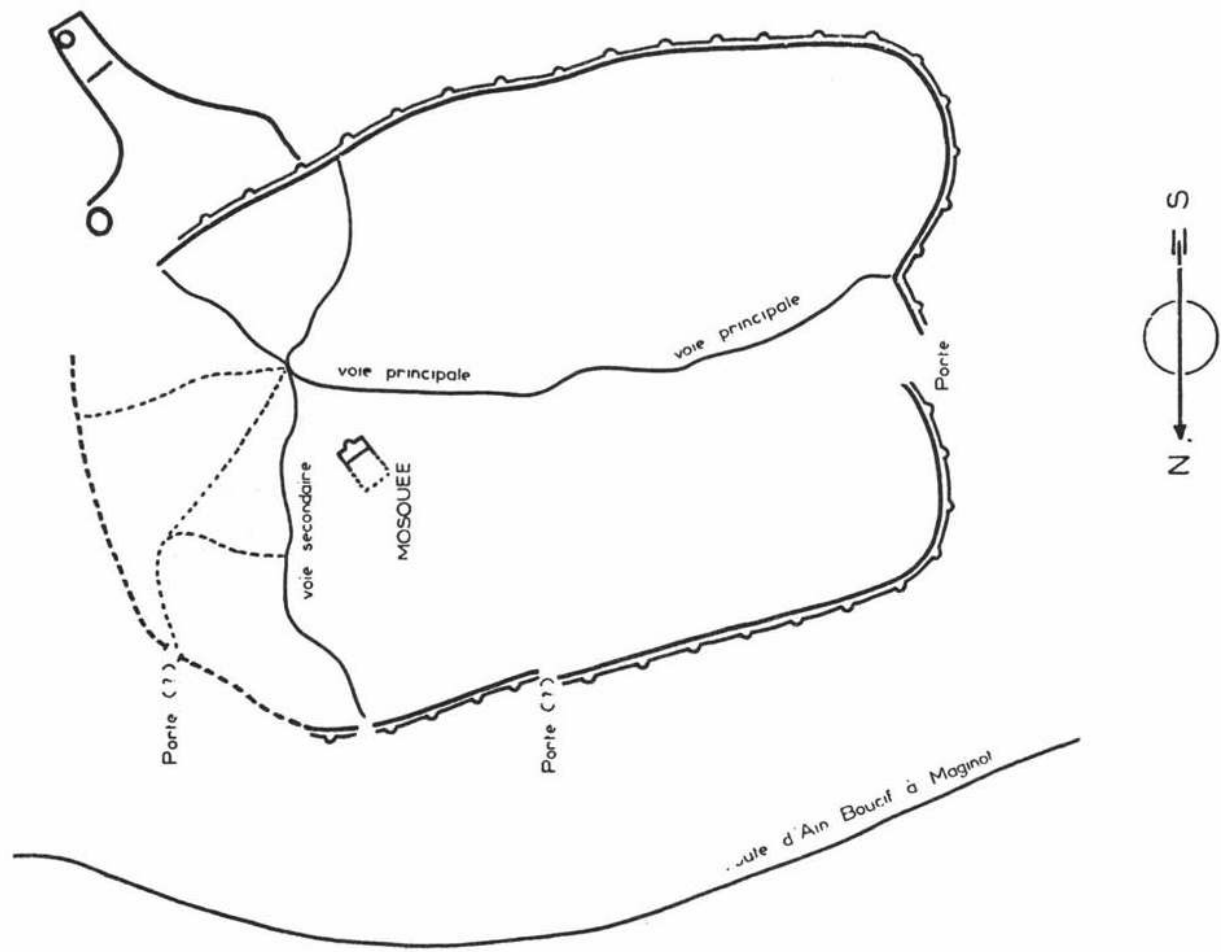

8 En fait, Buluggīn apparaît comme un très fidèle lieutenant, respectueux de la parole donnée et toutes ses actions ne paraissent avoir qu'un seul but, conserver intact le patrimoine mag̉ribin des Fāțimides. A la mort du calife al-Mu'izz, auquel il avait prêté serment (365/975-6), il renouvelle son allégeance à al-'Azīz et il lui fait parvenir de nombreux cadeaux (Bayān, I, 229). Au demeurant, l'homme reste un berbère et sans 
doute faut-il voir là une des raisons qui ont déterminé le calife à lui adjoindre des sortes de vice-rois ('âmil) d'origine arabe sur lesquels repose l'administration du pays. Lorsqu'Abd Allāh b.Muḥammad aura écarté son rival Ziyādat Allāh, c'est lui qui, en fait, gouvernera l'Ifrīqiya. Il aura sa garde noire personnelle comme un souverain et il se fera bâtir un palais, Buluggīn est trop occupé au Magirib central pour contrôler la gestion de son kāatib (le terme de vizīr n'apparaît nulle part à cette époque).

9 Au demeurant, on est enclin à penser que le chef șanhāğa, excellent meneur d'hommes, ne se trouve à l'aise qu'au sein de sa tribu, il a, semble-t-il, été peu préparé à la direction d'un pays de vieille civilisation citadine tel que l'Ifrīqiya, et il est fort probable que le montagnard berbère se sent peu à l'aise en compagnie des lettrés arabes de Kairouan.

On vante à l'envi la beauté des enfants de Manād, celle de Zīrī entre autres, son courage, son énergie, sa force, sa vaillance au combat. Le choix, par Zīrī, entre tous ses nombreux fils, de Buluggīn qu'il associe à son commandement nous autorise à penser que le fils est digne du père. Sa seule présence à la tête d'une armée fait fuir l'ennemi. En fait, l'essentiel de son " règne » se passe en combats, il est plus souvent à Achîr qu'à Șabra al-Manșūriyya. Sa famille y séjourne, son fils et successeur (le futur al-Manșūr) y est né et c'est à Achîr qu'il apprendra son accession au trône de Kairouan après la mort de Bulugginn.

11 En définitive, le choix du calife devait se révéler le meilleur. Al-Mu'izz avait fort bien jugé l'homme et il le savait digne de sa confiance.

\section{BIBLIOGRAPHIE}

GOLVIN L., Le Magrib central à l'époque des Zirides, Paris, A.M.G., 1957.

Id., « Buluggīn, fils de Ziri, prince berbère », R.O.M.M., 35, 1983, p. 93-113.

IBN IDARI, Bayân.

IBN KHALDOUN, Histoire des Berbères, trad. de Slane, Paris, 1969,1.1, p. 271 ; t. II, p. 6, 8, 9, 131, 149,

$548,550,689$; t. HI, p. 218, 234 et s., 256, 257, 259, 262, 294.

IDRIS R.-H., La Berbérie orientale sous les Zirides.

MAQRIZI, Hitat et Ihi'a.

MARÇAIS G., La Berbérie musulmane et l'Orient au Moyen-Age, Paris, 1946, p. 152, 156-159.

QADI AL-MU MAN, Iftitāh al-da'wa.

INDEX

Mots-clés : Algérie, Biographie 